\title{
Therapeutic effect of herb residue fermentation supernatant on spleen-deficient mice
}

\author{
XIAOXIAO ZHAO ${ }^{1}$, TINGTAO CHEN ${ }^{1}$, FANJING MENG ${ }^{1}$, HUAN WANG $^{2}$, PUYUAN TIAN $^{2}$, \\ XIANYAO TANG ${ }^{1}$, XIN WANG $^{2}$, XIAOLEI WANG ${ }^{1}$, HONGBO XIN $^{1}$ and HUA WEI $^{3}$ \\ ${ }^{1}$ Institute of Translational Medicine, Nanchang University, Nanchang, Jiangxi 330031; ${ }^{2}$ School of Life Sciences; \\ ${ }^{3}$ Jiangxi-OAI Joint Research Institute, Nanchang University, Nanchang, Jiangxi 330047, P.R. China
}

Received March 31, 2017; Accepted November 3, 2017

DOI: $10.3892 / \mathrm{mmr} .2017 .8150$

\begin{abstract}
To minimize the waste of active ingredients present in herb residues, in the present study, probiotics of Bacillus subtilis, Aspergillus oryzae and Lactobacillus plantarum M3 were selected to reuse herb residues from Jianweixiaoshi tablets, and the therapeutic effects of the herb residue fermentation supernatant were evaluated using a spleen-deficient mouse model. The results of the present study indicated that the fermentation supernatant may effectively improve the immunity of mice, as measured by body weight, spleen and thymus index, and inflammatory cytokines, including interleukin (IL)-2, IL-4 and interferon- $\gamma$. The viable cell count and denaturing gradient gel electrophoresis results indicated that the fermentation supernatant markedly enhanced bacterial diversity and the number of lactobacilli in mouse intestines. Therefore, the combination of the Jianweixiaoshi herb residue and probiotics provided a novel method to reuse herb residues and may in the future contribute to the treatment of spleen deficiency.
\end{abstract}

\section{Introduction}

According to the spleen-stomach theory in traditional Chinese medicine (TCM), the spleen is not anatomically, physiologically or pathophysiologically synonymous with one organ as it is in western medicine $(1,2)$. In TCM, the term spleen is used to describe the digestive system, including its vegetative nervous system, immunity, hemopoiesis, muscle metabolism, endocrine

Correspondence to: Professor Tingtao Chen, Institute of Translational Medicine, Nanchang University, 1299 Xuefu Road, Nanchang, Jiangxi 330031, P.R. China

E-mail: chentingtao1984@163.com

Professor Hua Wei, Jiangxi-OAI Joint Research Institute, Nanchang University, 235 East Nanjing Road, Nanchang, Jiangxi 330047, P.R. China

E-mail: weihua114@live.cn

Key words: herb residue, probiotics, denaturing gradient gel electrophoresis, lactobacilli, diarrhea function, hepatic metabolic function, and protein, nucleotide, energy, water and salt metabolism $(1,2)$. Spleen deficiency is characterized by symptoms including epigastralgia, flatulence, lack of appetite, wilted complexion, loose stools, lassitude and fatigue. Spleen deficiency is one of the most common digestive diseases in China and is frequently associated with imbalances in the gastrointestinal microflora $(3,4)$. Therefore, clinical studies are being conducted in order to identify an association between TCM and intestinal microbiota and to contribute to the treatment of spleen deficiency $(1,5,6)$.

Jianweixiaoshi tablets were approved by the Chinese Ministry of Health as one of the national protected traditional medicines in 1995 and were listed as the first class of over-the-counter drugs in 1999. Jianweixiaoshi tablets, containing hawthorn, malt, tangerine peel, Radix Pseudostellariae and yam, are used for treatment of indigestion, anorexia and abdominal distension, via invigoration of the stomach and tonification the spleen. Jianweixiaoshi tablets have been demonstrated to promote gastrointestinal peristalsis and gastric secretion of digestive juices, and enhance the activity of pepsin, general physique and immune function (7). In China, sales of Jianweixiaoshi tablets generate $>1.2$ billion renminbi in income each year, although they also produce $\sim 100,000$ tons of herb residues which are primarily used in food additives $(7,8)$.

Herb residues are by-products of TCM materials extracted by water or ethanol, and $\sim 30-50 \%$ of the medically active ingredients remain inaccessible (9). The microorganism fermentation theory in TCM suggests that digestive enzymes, including cellulase, protease, pectinase, lignin and lipase, produced by microorganisms may effectively degrade plant cell walls, expand the intercellular region and improve the yield of extraction of active ingredients (10). In addition, microorganisms may degrade macromolecules to smaller molecules, making them accessible for direct absorption by the human body, reduce the side effects of drugs by degrading toxic substances and introduce novel therapeutic effects by biological modification. In addition, probiotics have been defined as 'live microorganisms that, when administered in adequate amounts, confer a health benefit on the host', including anti-carcinogenic and anti-mutagenic properties, immune stimulation and lowering of serum cholesterol $(11,12)$. Probiotics may be used for the prevention and treatment of certain pathological conditions $(13,14)$. 
In the present study, herb residues of Jianweixiaoshi tablets were reused via probiotics, a spleen-deficient mouse model was established and the therapeutic effect of the herb residue fermentation supernatant on spleen deficiency was evaluated.

\section{Materials and methods}

Preparation of herb residue extract and fermentation supernatant. The herb residue of Jianweixiaoshi tablets was obtained from Jiangsu Yangtze River Pharmaceutical Group Company, Ltd. (Taizhou, China) and homogenized for $2 \mathrm{~h}$ using a pulper. Bacillus subtilis (isolated from Douchi and stored in Professor Chen's laboratory at Nanchang University), Aspergillus oryzae (isolated from Douchi and stored in Professor Chen's laboratory as above) and Lactobacillus plantarum M3 (isolated from sourdough and stored in in Professor Chen's laboratory as above) bacteria (all $10^{8}$ colony forming $\mathrm{U} / \mathrm{ml}$ ) were used as the inoculum for the preparation of the herb residue fermentation supernatant. B. subtilis and $A$. oryzae were added to the herb residue for $24 \mathrm{~h}$, and L. plantarum M3 was added for $24-36 \mathrm{~h}$ at $37^{\circ} \mathrm{C}$. Fermented products were subsequently centrifuged for $30 \mathrm{~min}$ at $1,000 \mathrm{x} \mathrm{g}$ at $4^{\circ} \mathrm{C}$ in a refrigerated centrifuge (Hunan Xiangyi Laboratory Instrument Development Co., Ltd., Changsha, China) to obtain the fermentation supernatant.

Spleen-deficient mouse model and treatment. The present study was approved by the Ethical Committee of the Second Affiliated Hospital of Nanchang University (Nanchang, China) and all methods were performed in accordance with the approved guidelines.

A total of 30 specific pathogen free 6-8-week-old male C57BL/6 mice weighting 20-30 g were housed and fed a commercial diet with water ad libitum. All mice were purchased from the Hebei Center for Disease Control and Prevention (Hebei, China), housed five per cage, on a $12-\mathrm{h}$ light/dark cycle at $23 \pm 2^{\circ} \mathrm{C}$ and at $50 \pm 10 \%$ relative humidity. To establish the spleen-deficient mice model, $20 \mathrm{ml} / \mathrm{kg} /$ day $100 \%$ rhubarb decoction (supplied by Jiangxi Provincial Hospital of Traditional Chinese Medicine, Jiangxi, China) was administered intragastrically to mice for 7 days. All control animals were treated with the equivalent volume of PBS. Subsequently, model mice were divided into 3 groups: i) The modeling group $(n=10)$, in which mice were only administered PBS; ii) the probiotics + drug residues group $(n=10)$, in which mice were administered herb residue fermentation supernatant $(0.1 \mathrm{ml} / 20 \mathrm{~g})$; and iii) the Jianweixiaoshi tablets group $(\mathrm{n}=10)$, in which mice were administered Jianweixiaoshi tablets $(0.1 \mathrm{ml} / 20 \mathrm{~g})$. Mouse feces were collected at four time-points: i) During the control stage, on day 0 , prior to treatment; ii) during the modeling stage, on day 7 , following treatment with rhubarb decoction; iii) during the treatment stage, on day 14 , following drug treatment; and iv) during the recovery stage, on day 21. In each group, feces of three mice from the modeling, probiotics + drug residue and Jianweixiaoshi tablets groups were randomly selected and used for denaturing gradient gel electrophoresis (DGGE) analysis.

Determination of immune indices and inflammatory factors. A total of $24 \mathrm{~h}$ following the final drug administration, five animals in each group were sacrificed by decapitation. Tail vein method was used to obtain the whole blood, and serum was obtained by the centrifugation of clotted blood at $2,500 \mathrm{x} \mathrm{g}$ for $15 \mathrm{~min}$ at $4^{\circ} \mathrm{C}$, and interleukin (IL)-2, IL-4 and interferon $-\gamma($ IFN- $\gamma)$ were determined using ELISA kits for IL-2 (88-7024-88; Mouse IL-2 ELISA Ready-SET-Go!), IL-4 (88-7044-22; Mouse IL-4 ELISA Ready-SET-Go!) and IFN- $\gamma$ (BMS606; Mouse IFN- $\gamma$ Platinum ELISA; all from eBioscience; Thermo Fisher Scientific, Inc., Waltham, MA, USA) (15). Spleen and thymus were harvested from mice and weighed immediately. Thymus and spleen indices were calculated according to the following formula: Thymus or spleen index $=$ [(weight of thymus or spleen $) /$ body weight $]$ x 100 .

Viable cell count. Fresh fecal samples were subjected to treatment within $2 \mathrm{~h}$ following collection. All samples were serially diluted 10 -fold with saline solution and $300-\mu 1$ solutions resulting from each dilution were separately plated on a brain-heart infusion agar supplemented with $10 \%$ sterile skimmed milk (Beijing Land Bridge Technology Co., Ltd., Beijing, China) for total anaerobic bacteria, and incubated anaerobically at $37^{\circ} \mathrm{C}$ for 36 h. De Man, Rogosa and Sharpe agar (Oxoid; Thermo Fisher Scientific, Inc.) was used for anaerobic culture of Lactobacilli at $37^{\circ} \mathrm{C}$ for $24 \mathrm{~h}$. Enterococci were aerobically cultured at $37^{\circ} \mathrm{C}$ for $24 \mathrm{~h}$ on Slanetz-Bartley medium agar and MacConkey agar (both from Oxoid; Thermo Fisher Scientific, Inc.) was used for aerobic culture of Enterobacteria at $37^{\circ} \mathrm{C}$ for $24 \mathrm{~h}$ (16-18).

DGGE and statistical analysis. DNA was isolated using bead-beating method (19). Following phenol-chloroform extraction, DNA was precipitated with $75 \%$ ethanol and resuspended in $50 \mu \mathrm{l}$ TE buffer (10 mM Tris-Cl, $1 \mathrm{mM}$ EDTA; $\mathrm{pH}$ 7.6). Primers, including 357 forward (5'-TACGGGAGG CAGCAG-3') and 519 reverse (5'-ATTACCGCGGCTGCT GG-3'), were used to amplify total bacterial DNA, and Lac1 (5'-AGCAGTAGGGAATCTTCCA-3') and Lac2 (5'-ATT YCACCGCTACACATG-3') were used to amplify DNA from Lactobacillus species. GC clam-in primers were selected to generate GC-enriched polymerase chain reaction (PCR) products suitable for separation by DGGE. Subsequently, a PCR was performed using the Taq DNA Polymerase kit (Takara Biotechnology Co., Ltd., Dalian, China) in a Biosci PCR system, with 30 cycles of $94^{\circ} \mathrm{C}$ for $30 \mathrm{sec}, 56^{\circ} \mathrm{C}$ for $30 \mathrm{sec}$, and $72^{\circ} \mathrm{C}$ for $60 \mathrm{sec}$. Amplicons of $16 \mathrm{~S}$ ribosomal RNA were used for sequence-separation by DGGE, as previously described $(20,21)$. DGGE was performed on $8 \%$ polyacrylamide gels containing acrylamide, bisacrylamide, formamide and a gradient of 35-65\% urea. Tris- $\mathrm{HCl}$ (40 mM; pH 8.0) was used as the electrophoresis buffer in a Bio-Rad DGGE system (Bio-Rad Laboratories, Inc., Hercules, CA, USA). Electrophoresis was initiated by a pre-run for $5 \mathrm{~min}$ at $220 \mathrm{~V}$ followed by run at a fixed voltage of $85 \mathrm{~V}$ for $16 \mathrm{~h}$ at $60^{\circ} \mathrm{C}$. Gels were stained with $\mathrm{AgNO}_{3}$ and developed following electrophoresis. Subsequently, gels were covered with cellophane membranes and dried overnight at $4^{\circ} \mathrm{C}$. DGGE patterns were subsequently normalized and analyzed using Bionumeric software (version 2.0; Applied Maths, Sint-Martens-Latem, Belgium). During the processing, lanes were defined and the background was subtracted. In the process of normalization, differences in the intensity of the lanes were compensated 

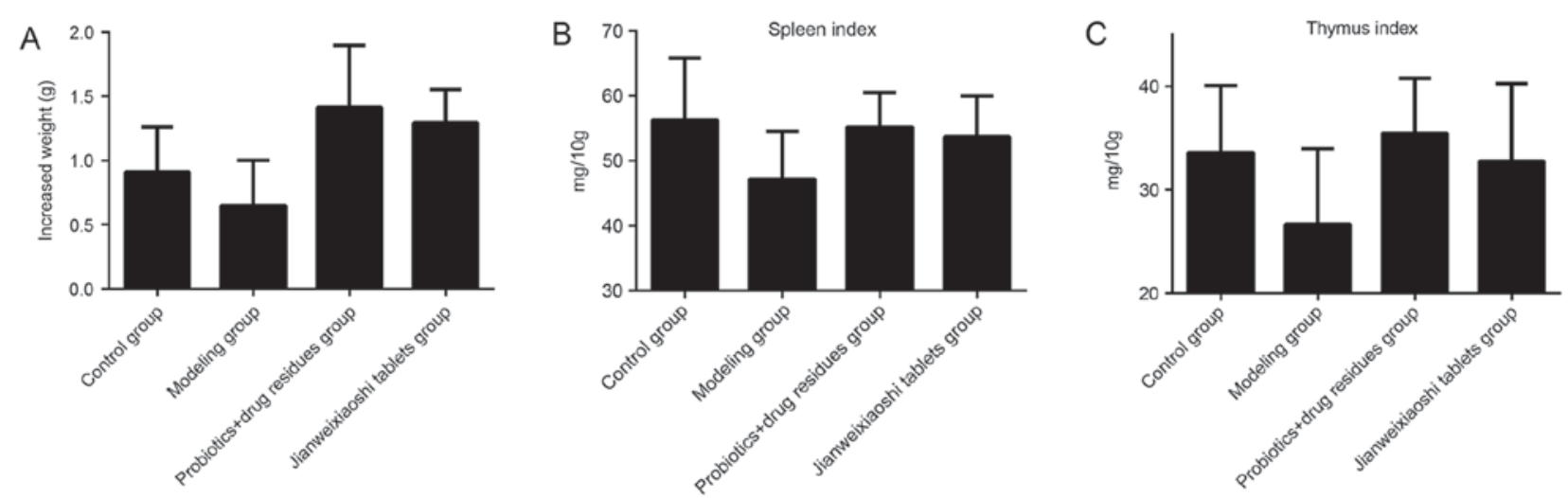

Figure 1. Effect of herb residue fermentation supernatant on mice. The effect on (A) weight, (B) spleen index and (C) thymus index. Data are expressed as the mean \pm standard deviation.
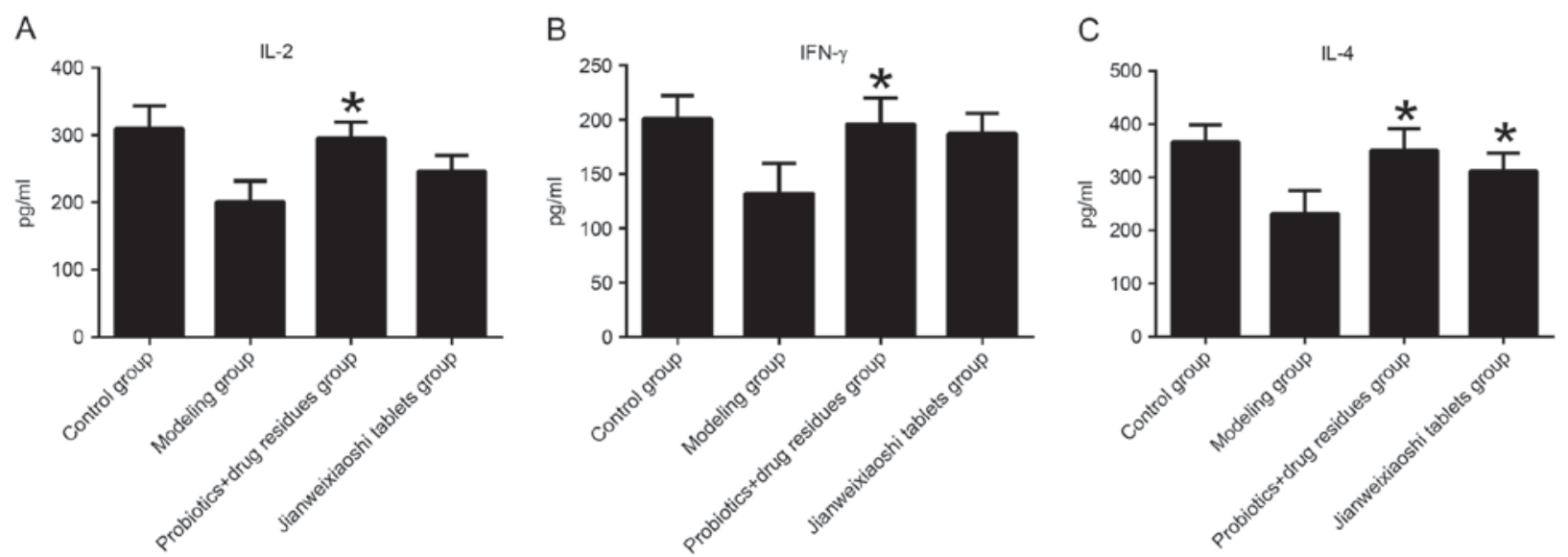

Figure 2. Effect of herb residue fermentation supernatant on immunity. The effect of herb residue fermentation supernatant on (A) IL-2, (B) IFN- $\gamma$ and (C) IL-4 in mouse serum. Data are expressed as the mean \pm standard deviation. ${ }^{*} \mathrm{P}<0.05$ vs. respective modeling group. IL, interleukin; IFN- $\gamma$, interferon- $\gamma$.

and the association matrix was calculated. Clustering was performed using the Pearson correlation and unweighted pair group method with arithmetic mean (UPGMA) methods.

Sequencing of DGGE bands. Bands of interest were excised from the gel using a sterile blade and incubated overnight at $4^{\circ} \mathrm{C}$ in Tris-EDTA buffer ( $\mathrm{pH}$ 8.0) to allow for DNA diffusion out of the polyacrylamide matrix. The solution was used directly for further amplifications. For sequencing, eluted DNA was amplified using the same primer pairs and conditions as described above, without the GC clamp. PCR products for sequencing were purified using a QIAquick PCR purification kit (Qiagen $\mathrm{GmbH}$, Hilden, Germany). PCR products were subcloned using the pMD18-T vector system I (Takara Biotechnology Co., Ltd.) according to the manufacturer's instructions. E. coli DH5 $\alpha$ cells (Beijing Tiangen Biochemical Technology Co., Ltd., Beijing, China) were subjected to electrotransformation with recombinant plasmids. Selection of transformants was performed on lysogeny broth agar (Oxoid; Thermo Fisher Scientific, Inc.) containing 100 mg/ml ampicillin. Transformants were randomly selected and sequenced by Invitrogen (Thermo Fisher Scientific, Inc.) (22-24).

Statistical analysis. Data are presented as the mean \pm standard deviation. Data were analyzed using SPSS software (version 13.0; SPSS Inc., Chicago, IL, USA) using one-way analysis of variance with the least significant difference post hoc test. $\mathrm{P}<0.05$ was considered to indicate a statistically significant difference.

\section{Results}

Treatment with fermentation supernatant increases body weight, thymus and spleen indices in mice. Compared with the control group, treatment with rhubarb reduced body weight, spleen index and thymus index (Fig. 1) in the modeling group, and presented depressive behavior, constipation, unkempt fur and poor appetite. Treatment with herb residue fermentation supernatant and Jianweixioashi tablets resulted in an increase in body weight, spleen index and thymus index, although these differences were not statistically significant.

Levels of $I L-2, I L-4$ and $I F N-\gamma$ in serum. Treatment with rhubarb decreased the levels of IL-2, IL-4 and IFN- $\gamma$ in the modeling group, compared with the control group. Administration of probiotics with herb residues significantly increased levels of IL-2, -4 and IFN- $\gamma$, compared with the modeling group (all $\mathrm{P}<0.05$; Fig. 2). Jianweixioashi tablets significantly increased levels of IL-4, compared with the modeling group $(\mathrm{P}<0.05)$. 
A

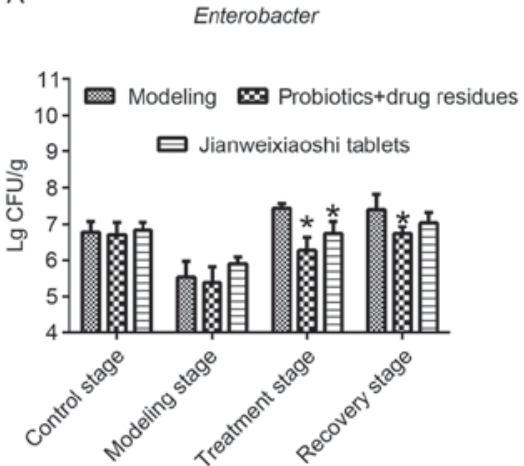

B

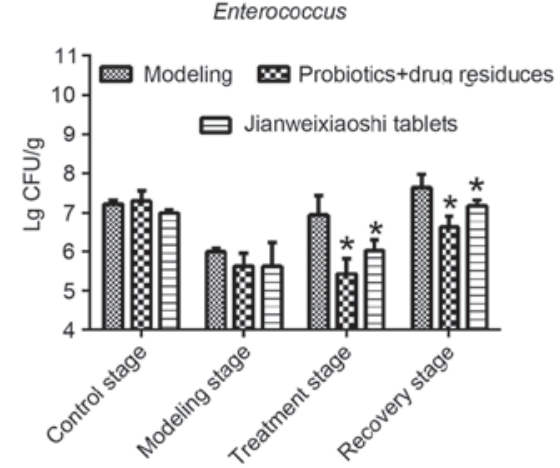

C

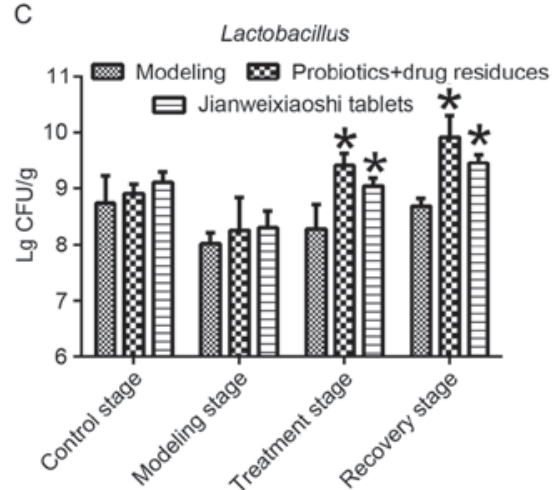

Figure 3. Effect of herb residue fermentation supernatant on the number of intestinal bacteria. The effect on (A) Enterobacter, (B) Enterococcus and (C) Lactobacillus. Data are expressed as the mean \pm standard deviation. ${ }^{*} \mathrm{P}<0.05$ vs. respective modeling group. Lg, Log; CFU, colony forming unit.

A

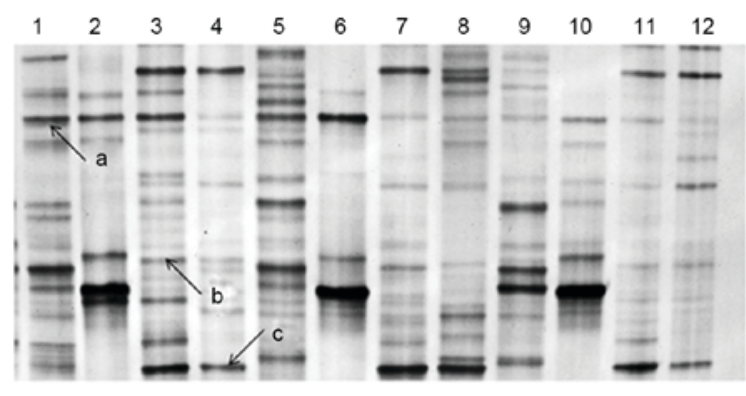

B

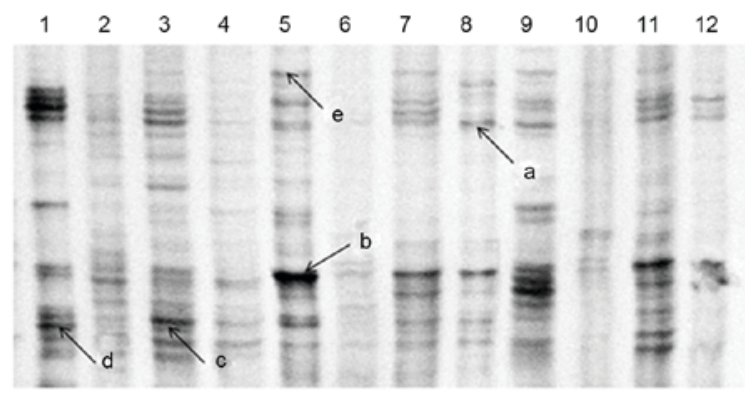

C

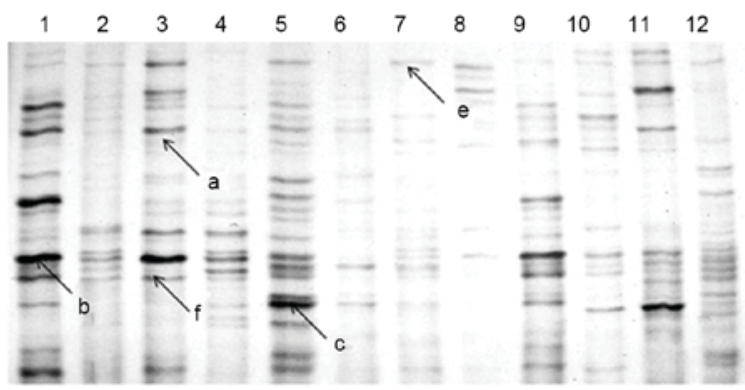

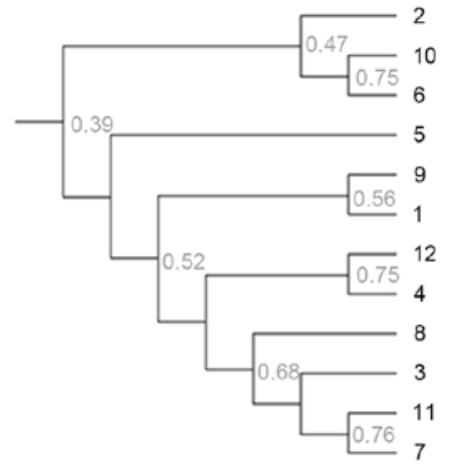
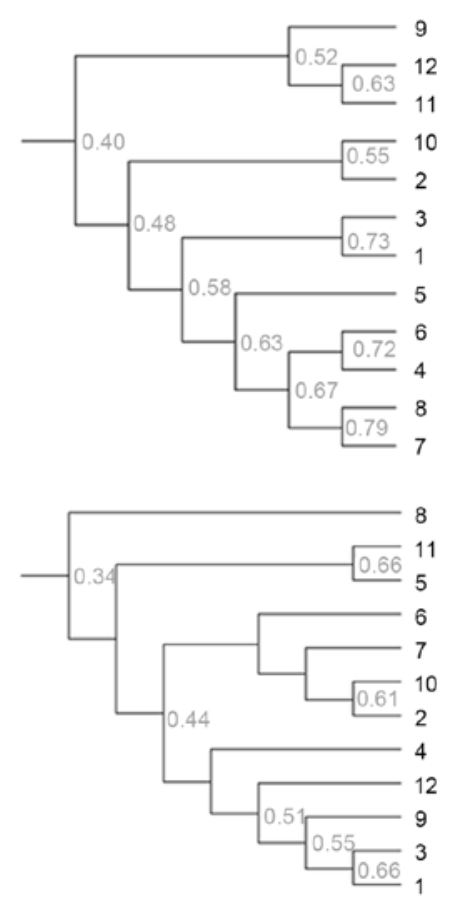

Figure 4. DGGE profile and unweighted pair group method with arithmetic mean analysis of fecal microbiota using bacterial primers. DGGE profile of (A) the modeling group, (B) the probiotics + drug residues group and (C) the Jianweixiaoshi tablets group. Lanes 1-3, control stage samples; lanes 4-6, modeling stage samples; lanes, 7-9 treatment stage samples; and lanes 10-12, recovery stage samples. a, uncultured bacterium; b, Lactobacillus murinus; c, Enterococcus sp.; d, Clostridium sp.; e, uncultured bacterium; f, uncultured bacterium. DGGE, denaturing gradient gel electrophoresis.

Effects of fermentation supernatant on microbial number in vivo. The effects of the fermentation supernatant on the viable number of Enterococci, Enterobacteria and Lactobacilli were determined in the present study. Viable cell counts indicated that, during the treatment stage, fermentation supernatant and Jianweixioashi tablets increased the number of Lactobacilli, and reduced the number of Enterococci and Enterobacteria, compared with the modeling group (all $\mathrm{P}<0.05$; Fig. 3). During 
Table I. Strains identified from mouse intestines by denaturing gradient gel electrophoresis using bacterial primers and Bacillus primers.

A, Bacterial primers

\begin{tabular}{|c|c|c|c|}
\hline Strain no. & Closest relatives & Similarity, \% & GenBank no. \\
\hline $\mathrm{a}$ & Uncultured bacterium & 100 & HQ321493.1 \\
\hline $\mathrm{b}$ & Lactobacillus murinus & 100 & HQ668465.1 \\
\hline $\mathrm{c}$ & Enterococcus sp. & 100 & JF910016.1 \\
\hline d & Clostridium sp. & 100 & JF813180.1 \\
\hline $\mathrm{e}$ & Uncultured bacterium & 100 & GU606372.1 \\
\hline $\mathrm{f}$ & Uncultured bacterium & 100 & JF837882.1 \\
\hline
\end{tabular}

$\mathrm{B}$, Bacillus primers

\begin{tabular}{|c|c|c|c|}
\hline Strain no. & Closest relatives & Similarity, \% & GenBank no. \\
\hline $\mathrm{a}$ & Uncultured bacterium & 99 & НM363549.1 \\
\hline $\mathrm{b}$ & Uncultured bacterium & 100 & EU491355.1 \\
\hline c & Lactobacillus murinus & 100 & HQ668465.1 \\
\hline d & Uncultured bacterium & 100 & HM363550.1 \\
\hline $\mathrm{e}$ & Uncultured bacterium & 100 & EU475615.1 \\
\hline $\mathrm{f}$ & Uncultured bacterium & 100 & EU006313.1 \\
\hline g & Escherichia fergusonii & 100 & HQ259962.1 \\
\hline h & Uncultured bacterium & 100 & FJ881122.1 \\
\hline
\end{tabular}

the recovery stage, fermentation supernatant significantly inhibited the growth of Enterococci and Enterobacteria, and promoted the growth of Lactobacilli, compared with the modeling group $(\mathrm{P}<0.05)$.

Effects of the herb residue fermentation supernatant on bacterial diversity in vivo. The results of the DGGE analysis indicated that an uncultured bacterium, L. murinus, and Enterococcus sp. were the dominant bacteria in all groups throughout the experiments. In addition, the DGGE profile indicated that treatment with rhubarb markedly reduced the band number, while the administration of fermentation supernatant and Jianweixiaoshi tablets enhanced the bacterial diversity in the treatment and recovery stages (Fig. 4; Table IA). However, the results of the UPGMA analysis demonstrated low levels of similarity between bacteria in the control, treatment and recovery stages in the probiotics + drug residues and Jianweixiaoshi tablets treatment groups.

Effects of the herb residue fermentation supernatant on Bacillus diversity in vivo. As demonstrated by Bacillus DGGE profiles, treatment with rhubarb induced an effect on L. murinus, and uncultured bacteria d and f (Fig. 5). L. murinus was the dominant bacterium in all groups and during all stages. In addition, treatment with rhubarb eliminated uncultured bacterium d during the modeling stage in the probiotics + drug residue treatment group, while treatment with fermentation supernatant recovered the growth of uncultured bacterium d during the treatment and recovery stages (Fig. 5; Table IB).

\section{Discussion}

Large amounts of microbes have been identified in human intestines, particularly lactic acid bacteria, forming a complex ecological community that influences physiological homeostasis and serves a role in maintaining human health, including protection against entero-pathogens, extraction of nutrients and energy, and maintenance of normal immune functions (25-28). Jianweixiaoshi tablets have been demonstrated to alleviate various spleen-stomach diseases associated with intestinal bacteria, and the active ingredients identified in herb residues demonstrated a therapeutic effect on these diseases $(29,30)$. Therefore, the combination of probiotics and herb residues may exert positive effects on spleen-stomach diseases.

In the present study, a spleen-deficient mouse model was established, which demonstrated symptoms comprising depressive behavior, constipation, unkempt fur and poor appetite $(5,6)$. When treated with the herb residue fermentation supernatant, the mice exhibited a minor increase in body weight, spleen index and thymus index, suggesting that the fermentation supernatant was able to enhance growth and immunity in the mice.

Cytokines serve a role in immune responses. IL-2 and IFN- $\gamma$ are classified as T helper 1 cytokines, and stimulate the proliferation of cytotoxic $\mathrm{T}$ lymphocytes, helper $\mathrm{T}$ lymphocytes, natural killer cells, lymphokine activated killer cells and macrophages (31-34). IL-4 is a T helper 2 cytokine, serving a role in the stimulation of activated B-cells, the proliferation of T-cells and the differentiation of B cells into plasma cells, and it has additionally been implicated in the regulation of humoral 

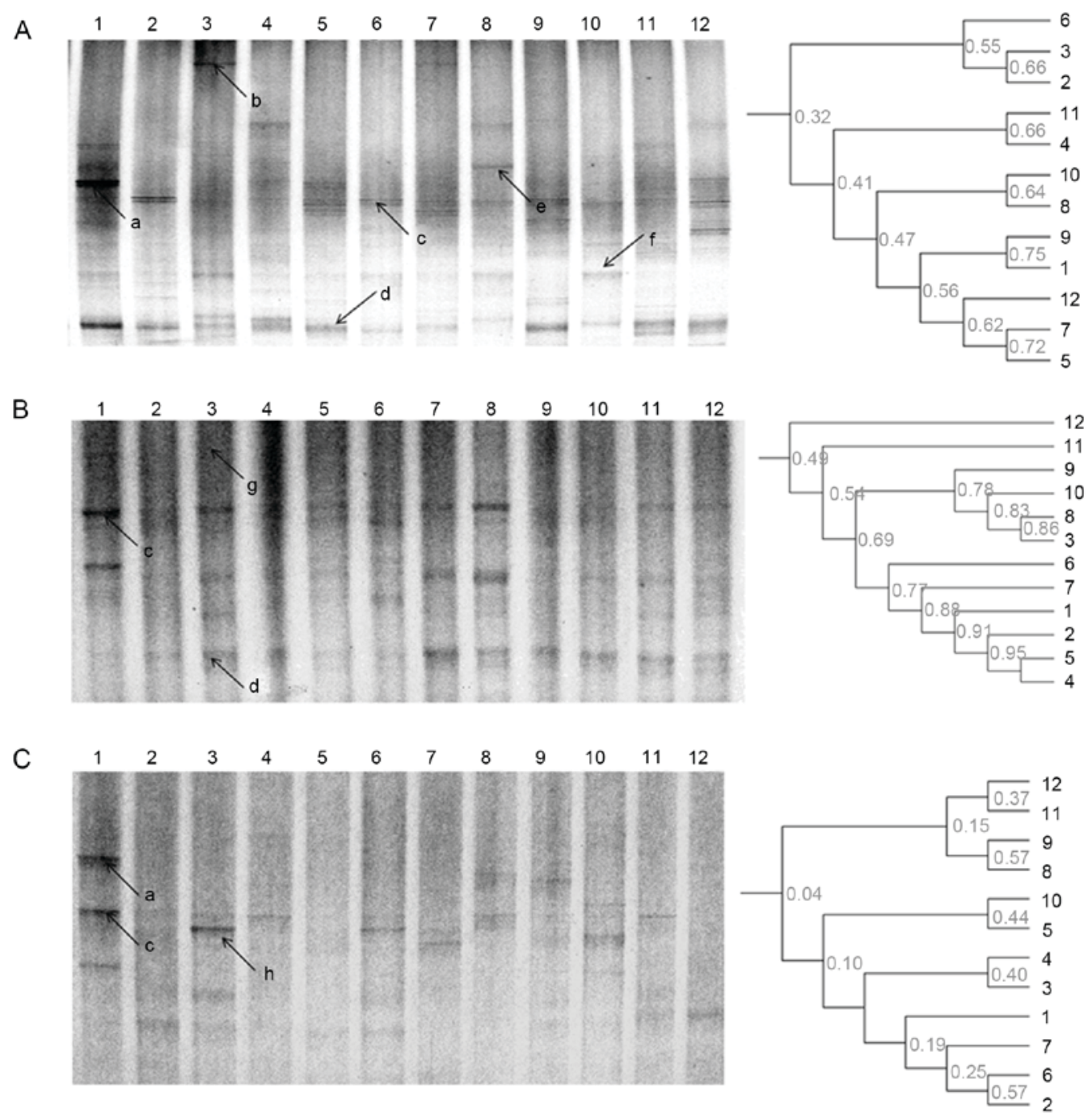

Figure 5. DGGE profile and unweighted pair group method with arithmetic mean analysis of fecal microbiota using Bacillus primers. DGGE profile of (A) the modeling group, (B) the probiotics + drug residues group and (C) the Jianweixiaoshi tablets group. Lanes 1-3, control stage samples; lanes 4-6, modeling stage samples; lanes, 7-9 treatment stage samples; and lanes 10-12, recovery stage samples. a, uncultured bacterium; b, uncultured bacterium; c, Lactobacillus murinus; d, uncultured bacterium; e, uncultured bacterium; f, uncultured bacterium; g, Escherichia fergusonii; h, uncultured bacterium. DGGE, denaturing gradient gel electrophoresis.

and adaptive immunity $(31,32)$. Therefore, increased production of IL-2, IL-4 and IFN- $\gamma$ indicated that the fermentation supernatant enhanced the immunity of the spleen-deficient mice.

Certain diseases, including obesity, malnutrition, inflammatory bowel disease, neurological disorders and cancer, may result from microbial imbalances (35-39). Considering the health-promoting effect of TCM and probiotics, fermentation supernatant may be hypothesized to enhance microbial diversity, promote the growth of probiotics and inhibit the growth of pathogens. The results of the viable cell counts in the present study indicated that the fermentation supernatant markedly enhanced the number of Lactobacilli and reduced the number of Enterococci and Enterobacteria during the treatment stage. The results of the DGGE analysis indicated that the fermentation supernatant enhanced bacterial diversity during the treatment and recovery stages. In the present study, low similarity levels between bacteria in the control, treatment and recovery stages indicated that a novel microbial balance was established by treatment with the fermentation supernatant.
The diversity of bacteria in host intestines contributes to more efficient host defenses from external invasion and, therefore, the reduced number of bands in the modeling group indicated weak resistance to foreign pathogens, while enhanced diversity in the fermentation supernatant group indicated recovery of intestinal health $(28,36,37,40)$.

In conclusion, in the present study, the therapeutic effects of herb residues from Jianweixiaoshi tablets were used for the treatment of spleen deficiency in mice in vivo. The results of the present study indicated that fermentation supernatant was able to enhance host immunity and inflammatory responses, by increasing the number and diversity of beneficial bacteria. Therefore, the present study demonstrated that the combination of Jianweixiaoshi herb residues and probiotics may, in the future, provide a novel method for the treatment of spleen deficiency.

\section{Acknowledgements}

The present study was supported by grants from the National Natural Science Foundation of China (grant nos. 81503364, 
31560264, 31360377, 91639106, 81270202 and 91339113), the National Basic Research Program of China (grant no. 2013CB531103) and grants from Jiangxi Province (grant nos. 20171BCB23028 and 20175526).

\section{References}

1. Zhang S, Zhao L, Wang H, Wang C, Huang S, Shen H, Wei W, Tao L and Zhou T: Efficacy of modified LiuJunZi decoction on functional dyspepsia of spleen-deficiency and qi-stagnation syndrome: A randomized controlled trial. BMC Complement Altern Med 13: 54, 2013.

2. Si FF, Tu JF, Liu TI and Liu ZJ: The effects of superfine powder on the total anti-oxidative ability and no of sijunzi decoction in spleen-deficient mice. Prog Vet Med 27: R28-R58, 2006.

3. Wu XN: Current concept of Spleen-Stomach theory and Spleen deficiency syndrome in TCM. World J Gastroenterol 4: 2-6, 1998

4. Peng Y, Wang Z, Lu Y, Wu CF, Yang JY and Li XB: Intestinal microflora molecular markers of spleen-deficient rats and evaluation of traditional Chinese drugs. World J Gastroenterol 15 2220-2227, 2009.

5. Zhao N, Zhang W, Guo Y, Jia H, Zha Q, Liu Z, Xu S and Lu A: Effects on neuroendocrinoimmune network of Lizhong Pill in the reserpine induced rats with spleen deficiency in traditional Chinese medicine. J Ethnopharmacol 133: 454-459, 2011.

6. Li LS, Qu RY, Wang W and Guo H: Significance of changes of gastrointestinal peptides in blood and ileum of experimental spleen deficiency rats. World J Gastroentero 9: 553-556, 2003.

7. Chen T, Xiong S, Jiang S, Wang M, Wu Q and Wei H: Effects of traditional Chinese medicines on intestinal bacteria: A review. Indian J Tradit Know 11: 401-407, 2012.

8. Meng F, Yang S, Wang X, Chen T, Wang X, Tang X, Zhang R and Shen L: Reclamation of Chinese herb residues using probiotics and evaluation of their beneficial effect on pathogen infection. J Infect Public Health 10: 749-754, 2017.

9. Zhou Y, Selvam A and Wong JW: Effect of Chinese medicinal herbal residues on microbial community succession and anti-pathogenic properties during co-composting with food waste. Bioresour Technol 217: 190-199, 2016.

10. Himmel ME, Ding SY, Johnson DK, Adney WS, Nimlos MR, Brady JW and Foust TD: Biomass recalcitrance: Engineering plants and enzymes for biofuels production. Science 315 : 804-807, 2007

11. Diplock AT, Aggett PJ, Ashwell M, Bornet F, Fern EB and Roberfroid MB: Scientific concepts in functional foods in Europe: Consensus document. Br J Nutr 81: S1-S27, 1999.

12. Hill C, Guarner F, Reid G, Gibson GR, Merenstein DJ, Pot B, Morelli L, Canani RB, Flint HJ, Salminen S, et al: Expert consensus document: The international scientific association for probiotics and prebiotics consensus statement on the scope and appropriate use of the term probiotic. Nat Rev Gastroenterol Hepatol 11: 506-514, 2014.

13. Jiang M, Deng K, Jiang C, Fu M, Guo C, Wang X, Wang X, Meng F, Yang S, Deng K, et al: Evaluation of the antioxidative, antibacterial, and anti-inflammatory effects of the aloe fermentation supernatant containing lactobacillus plantarum HM218749.1. Mediators Inflamm 2016: 2945650, 2016.

14. Liu D, Jiang XY, Zhou LS, Song JH and Zhang X: Effects of probiotics on intestinal mucosa barrier in patients with colorectal cancer after operation: Meta-analysis of randomized controlled trials. Medicine (Baltimore) 95: e3342, 2016.

15. Guo F, He H, Fu ZC, Huang S, Chen T, Papasian CJ, Morse LR, Xu Y, Battaglino RA, Yang XF, et al: Adipocyte-derived PAMM suppresses macrophage inflammation by inhibiting MAPK signalling. Biochem J 472: 309-318, 2015.

16. Wang X, Wu Q, Deng K, Wei Q, Hu P, He J, Liu H, Zheng Y, Wei H, Shah NP and Chen T: A novel method for screening of potential probiotics for high adhesion capability. J Dairy Sci 98: 4310-4317, 2015

17. Deng K, Chen T, Wu Q, Xin H, Wei Q, Hu P, Wang X, Wang X, Wei $\mathrm{H}$ and Shah NP: In vitro and in vivo examination of anticolonization of pathogens by Lactobacillus paracasei FJ861111.1. J Dairy Sci 98: 6759-6766, 2015.

18. Li S, Chen T, Dong S, Xiong Y, Wei H and Xu F: The effects of rebaudioside A on microbial diversity in mouse intestine. Food Sci And Technol Res 20: 459-467, 2014.
19. Chen T, Xiong S, Jiang S, Wang M, Wu Q and Wei H: Molecular identification of microbial community in Chinese douchi during post-fermentation process. Food Sci Biotechnol 20: 1633-1638, 2011.

20. Chen T, Wu Q, Li S, Xiong S, Jiang S, Tan Q, Zhang Z, Zhu D and Wei $\mathrm{H}$ : Microbiological quality and characteristics of probiotic products in China. J Sci Food Agric 94: 131-138, 2014.

21. Chen T, Wang M, Li S, Wu Q and Wei H: Molecular identification of microbial community in surface and undersurface douchi during postfermentation. J Food Sci 79: M653-M658, 2014.

22. Chen TT, Wang MJ, Li SJ, Wu QL and Wei H: Molecular Identification of Microbial Community in Surface and Undersurface Douchi During Postfermentation. J Food Sci 79: M653-M658, 2014

23. Chen T, Wang M, Jiang S, Xiong S and Wei $\mathrm{H}$ : The application of polymerase chain reaction-denaturing gradient gel electrophoresis (PCR-DGGE) method in microbial screening. Afr J Biotechnol 10: 9387-9395, 2011.

24. Chen T, Tan Q, Wang M, Xiong S, Jiang S, Li S, Luo C and Wei H: Identification of bacterial strains in viili by molecular taxonomy and their synergistic effects on milk curd and exopolysaccharides production. Afr J Biotechnol 10: 16969-16975, 2011.

25. Hooper LV, Littman DR and Macpherson AJ: Interactions between the microbiota and the immune system. Science 336: 1268-1273, 2012.

26. Nelson MH, Diven MA, Huff LW and Paulos CM: Harnessing the microbiome to enhance cancer immunotherapy. J Immunol Res 2015: 368736, 2015

27. Sivan A, Corrales L, Hubert N, Williams JB, Aquino-Michaels K, Earley ZM, Benyamin FW, Lei YM, Jabri B, Alegre ML, et al: Commensal bifidobacterium promotes antitumor immunity and facilitates anti-PD-L1 efficacy. Science 350: 1084-1089, 2015.

28. Zhernakova A, Kurilshikov A, Bonder MJ, Tigchelaar EF, Schirmer M, Vatanen T, Mujagic Z, Vila AV, Falony G, Vieira-Silva S, et al: Population-based metagenomics analysis reveals markers for gut microbiome composition and diversity. Science 352: 565-569, 2016.

29. Zhang ZB, Peiy Y and Liu W: Jianweixiaoshi tablets determination of hesperidin content tesr. J Pract Tradit Chin Intern Med 4: 015, 2011 (In Chinese).

30. Min Y, Jing L, Jinjin M and Ting X: Effects of oridonin on activities of rabbit's intestinal smooth muscle. China Pharm 14: 015, 2012.

31. Liao W, Lin JX and Leonard WJ: IL-2 family cytokines: New insights into the complex roles of IL-2 as a broad regulator of T helper cell differentiation. Curr Opin Immunol 23: 598-604, 2011.

32. Gaffen SL and Liu KD: Overview of interleukin-2 function, production and clinical applications. Cytokine 28: 109-123, 2004.

33. Wheelock EF: Interferon-like virus-inhibitor induced in human leukocytes by phytohemagglutinin. Science 149: 310-311, 1965.

34. Green JA, Cooperband SR and Kibrick S: Immune specific induction of interferon production in cultures of human blood lymphocytes. Science 164: 1415-1417, 1969.

35. Browne HP, Forster SC, Anonye BO, Kumar N, Neville BA, Stares MD, Goulding D and Lawley TD: Culturing of 'unculturable' human microbiota reveals novel taxa and extensive sporulation. Nature 533: 543-546, 2016.

36. Derrien M and van Hylckama Vlieg JE: Fate, activity, and impact of ingested bacteria within the human gut microbiota. Trends Microbiol 23: 354-366, 2015.

37. Kaeberlein T, Lewis K and Epstein SS: Isolating 'uncultivable' microorganisms in pure culture in a simulated natural environment. Science 296: 1127-1129, 2002.

38. Zheng P, Zeng B, Zhou C, Liu M, Fang Z, Xu X, Zeng L, Chen J, Fan S, Du X, et al: Gut microbiome remodeling induces depressive-like behaviors through a pathway mediated by the host's metabolism. Mol Psychiatry 21: 786-796, 2016.

39. Forsy the P, Kunze W and Bienenstock J: Moody microbes or fecal phrenology: What do we know about the microbiota-gut-brain axis? BMC Med 14: 58, 2016.

40. Karst SM: The influence of commensal bacteria on infection with enteric viruses. Nat Rev Microbiol 14: 197-204, 2016. 